P123 (continued)

with factor loadings less than 0.40 were eliminated, and a modified IJC survey was developed based on these findings. Next, the survey was re-piloted with youth participants in IJC, and data on survey completion time was collected. Researchers also conducted cognitive interviews with participants that investigated their understanding of the modified survey, and analyzed differences between the original and modified survey in regards to participants' preferences and ability to complete the survey.

Conclusions and Implications: A modified IJC survey was developed that decreased participant burden in time and ease of administration which will result in the collection of higher quality data and survey completion rate from youth participants.

Funding: Supplemental Nutrition Assistance Program Education 4-H Foundation, USDA 2011-67001-30101

\section{P124 Repeated Exposure Increases Children's Intake of Idaho Trout: A Pilot Study with Young Children}

Samantha Worden, MS, University of Idaho;

Jennie Davis, MS; Annie Roe, PhD, LDN, RD;

Madison Powell, PhD; Cady Hunt; Rachel Hernandez;

Sophia Dunlap; Samantha Ramsay, PhD, LDN, RD,

sramsay@uidaho.edu, University of Idaho, 875 Perimeter

Drive, MS 3183, Moscow, ID 83844

Objective: Determine whether RE increases children's preference and consumption of trout.

Study Design, Setting, Participants: Children's consumption of trout is supportive of overall health, but intake is below recommendations. Early childhood is a critical period for developing food preferences, particularly with repeated taste exposure (RE). However, RE of trout has not been evaluated in early childhood. Children ages 3-6 years $(n=11)$ attending a Child Development Lab were recruited to participate. All children completed a baseline activity, 8 repeated exposure activities, and a final tasting activity. Trout raised on four different diets were steamed and unseasoned, then offered to children in three bite sized portions.

Outcome Measures and Analysis: Descriptive statistics were reported. Differences in intake at baseline and final activities were determined using a t-test and differences in reported liking were determined using Wilcoxin signed-rank test.

Results: Children's age ranged from 25-59 months. Eight children were male (62\%) and 5 were female (38\%). The majority were from higher SES families (61\% at $\$ 59,000$ or above), and primarily Caucasian (92\%). For all trout samples, children's intake increased from baseline to final exposure, with a significant increase $[\mathrm{t}(21)=2.48, \mathrm{p}<.001]$ in one trout sample $(\mu 2 \mathrm{~g}$ baseline, $\mu 9 \mathrm{~g}$ final activity). Children's sum ranks for all trout samples from baseline to final activity indicated an increase in the reported liking, but was not statistically significant.

Conclusions and Implications: These results support previous literature on the benefit of repeated taste exposure, and indicate the need to continually offer trout to increase consumption that would support children's overall health.

Funding: None

\section{P125 Risk Characteristics and Behaviors for Ultra-processed Food Consumption in a Sample of Brazilian Children}

Lais Mais, MS, Federal University of São Paulo (UNIFESP); SarahWarkentin, MS, sarah_war@hotmail.com, Federal University of São Paulo (UNIFESP), Rua Loefgreen, 1647, São Paulo, Brazil; Juliana Vega, MS, Federal University of São Paulo (UNIFESP); Maria do Rosário Latorre, PhD, University of São Paulo (USP); Susan Carnell, PhD, Johns Hopkins University School of Medicine; José Augusto Taddei, PhD, Federal University of São Paulo (UNIFESP)

Objective: Identify food patterns among 2-9 year olds, and explore potential associations among less healthy dietary patterns, parental feeding practices and parent and child characteristics.

Study Design, Setting, Participants, Outcome Measures, Analysis: Cross-sectional study. Participants were parents of 2-9 year old children enrolled in private schools of São Paulo and Campinas, Brazil $(n=929)$. Parents completed a Food Frequency Questionnaire, feeding practices measured using a validated Brazilian version of the Comprehensive Feeding Practices Questionnaire and questionnaires regarding parent and child characteristics. First, we conducted a factor analysis on the Food Frequency Questionnaire to derive food patterns, followed by a univariate and a multivariate logistic regression model to identify predictors of less healthy dietary patterns.

Results: Two dietary patterns emerged: traditional foods, and ultra-processed foods. 'Healthy Eating Guidance' and 'Monitoring', factors of the Comprehensive Feeding Practices Questionnaire, were negatively associated with the ultra-processed food pattern, while the screen use during mealtimes, lower perceived parental responsibility for adequacy of food groups' intake, lower maternal education, and higher maternal weight status were positively associated with this pattern.

Conclusions and Implications: This is the first study to evaluate associations between less healthy dietary patterns of Brazilian 2-9 year olds, parental feeding practices and other risk characteristics. Our findings highlight demographic and behavioral factors within families that could be used to target tailored policies and interventions in risk populations for obesity and its consequences.

Funding: Brazilian CAPES - Coordenação de Aperfeiçoamento de Pessoal de Nível Superior; Brazilian CnPq-Conselho Nacional de Desenvolvimento Cientifico e Tecnologico 